Dijon, France, have continued their interests and research concerning the association of somnambulism and migraine in childhood. Among 25 children with migraine developing between 8 and 15 years of age, $7(28 \%)$ had a history of somnambulism beginning at age 5 to 10 years (mean 7 years). In normal controls and in children with epilepsy, the incidence of somnambulism was only 5 and $6 \%$, respectively. A history of somnambulism may be a useful aid in the diagnosis of migraine in a child with headaches. (Giroud M, Nivelon JL, Dumas R. Arch Fr Pediatr $1987 ; 44: 263-5)$.

COMMENT: The early differentiation of migraine from nonmigraine headache is important (1) to expedite relief by appropriate treatment and (2) to spare the child unnecessary radiological and other extensive testing. This study confirms that of Barabas G et al (Neurology 1983; 33; 948) that showed an incidence of sleep walking of $30 \%$ in migraineurs compared to 5 to 68 with learning disabilities. Additional childhood precursors of migraine include cyclic vomiting, abdominal pain, motion sickness, and paroxysmal vertigo.

\title{
TOLOSA-HUNT SYNDROME
}

The authors report a case in a 10.5 year old girl admitted to the Centre hospitalier Guy-de-Chauliac, Montpellier, France, with a left painful ophthalmoplegia. She had a convulsion with fever and a left facial palsy at 6 years of age and since then complained of headaches. Four years later she had diplopia, left-sided ocular pain and ptosis. On admission, there was a complete III nerve and a VI nerve paralysis on the left. CT, EEG, evoked potentials, spinal tap, blood and immunologic tests were normal. Steroid therapy resulted in a rapid remission. The authors point out that the diagnosis is by exclusion of local and systemic disease and that the syndrome is difficult to differentiate from ophthalmoplegic migraine. (Rapin, F, Echenne B. Arch Fr Pediatr 1987; 44: 299-301).

COMMENT: Tolosa, in 1954, described this syndrome as a periarteritic lesion of the carotid syphon with the clinical features of a carotid infraclinoidal aneurysm. Hunt et al, in 1961, invoked an indolent inflammation of the cavernous sinus and described the beneficial response to sternids.

Ophthalmoplegic migraine, in the differential diagnosis, has been reported in infants (Pediatrics 1978; 61;886) and usually presents early in childhood. The III nerve palsy develops 24 hours or more after the onset of the migraine headache and coincides with the stage of vasodilation; presumably it is due to a localized pressure effect of the carotid artery.

\section{INFECTIONS OF THE NERVOUS SYSTEM}

NEW ENGLAND LYME DISEASE IN ENGLAND

A 6 year old boy seen this month after recovery from severe neurological complications of Lyme disease prompts this report to alert pediatricians and neurologists to the increase in incidence of this seasonal infectious disease, especially among campers in the United States, Europe, and Australia.

The patient whose case was reported from St. Helier Hospital, Carshalton, Surrey, presented 6 months ago with headache, drowsiness, vomiting, photophobia, and neck stiffness. He was afebrile and had 